\title{
INOVAÇÃO E CIÊNCIA DA INFORMAÇÃO NO BRASIL: ANÁLISE DAS PUBLICAÇÕES DO ENANCIB E BRAPCI ENTRE 2006 E 2016
}

\author{
Juliana Fachin ${ }^{1}$ \\ Universidade Federal de Santa Catarina \\ julianafachin@gmail.com \\ Ursula Blattmann ${ }^{2}$ \\ Universidade Federal de Santa Catarina \\ ublattmann@gmail.com \\ William Barbosa Vianna ${ }^{3}$ \\ Universidade Federal de Santa Catarina \\ william.vianna@ufsc.br
}

\begin{abstract}
Resumo
Estudo exploratório e descritivo com objetivo conhecer o cenário das publicações científicas sobre inovação, disponíveis nos anais do ENANCIB entre 2006 e 2017 e publicações periódicas indexadas na BRAPCI, constituindo uma amostra de 121 documentos. A amostra documental aponta que a maior parte das pesquisas analisadas na informação como fonte para a tomada de decisões, na gestão da informação e do conhecimento para a inovação, e, mapeamento de estudos sobre inovação e suas derivações: aberta, incremental, social e radical. Para conhecer o cenário da publicação científica da área, obteve-se dados como: ano de publicação, título do periódico, quantidade de publicações e o indicativo de autoria e co-autoria. Conclui-se sobre a produção científica na área da Ciência da Informação que a inovação está direcionada ao objeto informação enquanto fonte no processo inovativo. Estudos de aplicação de inovação de produtos ou serviços ainda são incipientes.
\end{abstract}

Palavras-chave: Ciência da Informação. Inovação - Pesquisa. ENANCIB. BRAPCI. Publicação Científica.

\section{INNOVATION AND SCIENCE OF INFORMATION IN BRAZIL: ANALYSIS OF PUBLICATIONS OF ENANCIB AND BRAPCI BETWEEN 2006 AND 2016}

\begin{abstract}
Exploratory and descriptive study to know the scenario of scientific publications on innovation, available in the proccedings ENANCIB proccedings between 2006 and 2017 and also journals publications indexed in BRAPCI, constituting a sample of 121 documents. Documental sample indicates most of the research analyzed, such as information for decision making, information management and knowledge for innovation, and mapping of innovation studies and their derivations: open, incremental, social and radical. To know the scenario of the scientific publication of the area, register the data of the year of publication, journal title and number of publications for each, indicative of authorship and co-authorship. It concluded about the scientific production in the area of Information Science that innovation is directed to the object of information as a source in the innovative process. Application studies of product or service innovation are still incipient.
\end{abstract}

Keywords: Information Science. Innovation - research. ENANCIB. BRAPCI. Scientific publication.

\footnotetext{
${ }^{1}$ Doutoranda no Programa de Pós-Graduação em Ciência da Informação da UFSC. Bolsista Capes.

${ }^{2}$ Professora Dra. Departamento de Ciência da Informação, UFSC.

${ }^{3}$ Professor Dr. Departamento de Ciência da Informação, UFSC.
}

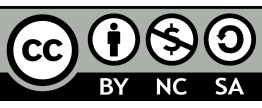




\section{INTRODUÇÃO}

As tecnologias de informação propiciam rápido desenvolvimento científico e tecnológico, por esse motivo inovar se torna cada vez mais imperativo, “[...] a tecnologia sempre desempenha um papel fundamental na disponibilização de opções radicalmente novas" (TIDD; BESSANT; PAVITT, 2008, p. 24), principalmente para as organizações, tanto para a criação como para a melhoria de processos, produtos e serviços. Os autores enfatizam que é incontestável que, as empresas que inovam têm em comum o sucesso como fator diferencial.

O processo de inovação depende prioritariamente do compartilhamento de informação e do uso de conhecimento interno e externo para as aplicações das atividades neste ambiente. Esse é o motivo pelo qual a Ciência da Informação estuda os elementos que enredam o ambiente inovador. Conforme Borko (1968, p. 01) trata-se de uma ciência interdisciplinar que "investiga as propriedades e o comportamento informacional, as forças que governam os fluxos de informação, e os significados do processamento da informação, visando à acessibilidade e a usabilidade ótima".

A Ciência da Informação constitui sua interdisciplinaridade com base nas ciências sociais atual, exige soluções inovativas e plurais. E se aproxima de várias áreas, utilizando teorias e métodos, para a aplicação de sua prática, emprestados da matemática, física, biologia, psicologia, sociologia, antropologia, semiologia e teoria da comunicação e de outras áreas que possam contribuir para a sua fundamentação teórica ou aplicada (ARAÚJO, 2003, p. 26).

Se considerarmos que a Ciência da Informação é interdisciplinar e se relaciona com outras áreas e estuda o comportamento, propriedades, fluxo da informação, processamento para a visibilidade e acessibilidade, logo, o processo de inovação está inserido no seu contexto e campo de estudo, por circundar um elemento comum, a informação. Landry (1995, p.318) indica que, "os principais pontos de vista dos problemas é olhar para as diferentes formas de conhecimento em que a própria produção do conhecimento foi conceituada". Por esse motivo carecem estudos amplos para abarcar os diversos campos e subcampos de interesse e aplicação, a informação também é aporte em outras áreas de conhecimento, por isso, a interdisciplinaridade visa a complementação de abordagens em pesquisa, compondo múltiplos olhares sobre um mesmo assunto. Esse estudo visa conhecer o cenário da publicação científica sobre inovação pelos pesquisadores da Ciência da Informação. 


\section{METODOLOGIA}

Esta pesquisa de caráter exploratório, "trata-se de uma observação não estruturada, ou assistemática: consiste em recolher e registrar os fatos da realidade" (RAMPAZZO, 2013, p.54),

Enquanto pesquisa descritiva quando aplica a observação e descrição de dados com base nos procedimentos bibliográfico e documental. Rampazzo (2013) especifica que a técnica, bibliográfica, procura utilizar vários tipos de fontes de informação, livros, artigos, publicações em meio eletrônico ou impresso; já a documental utiliza fonte primária, relatórios, leis, dados estatísticos.

Quanto a população e amostra, verificou-se em 02 junho de 2017 os anais do ENANCIB, disponíveis na página da ANCIB (2017) e na página da BRAPCI (2017) o que havia de publicação sobre Inovação. O termo empregado nas duas bases foi "inovação"4, restringindo a busca por título.

Nos documentos dos anais do ENANCIB foram recuperados 57 textos, ao aplicar o corte temporal 2006-2016 obteve-se 46 documentos. Ao verificar quais não tratavam do tema, foram excluídos 4 trabalhos da lista, restando 42, dos quais 11 eram pôster. Cabe ressaltar que na página da ANCIB encontra-se apenas as publicações dos eventos $\mathrm{I}$ ao $\mathrm{XV}$, os anais do evento XVI e XVII foram recuperados nas respectivas páginas dos eventos: XVI ENANCIB João Pessoa, PB (2015) e XVII - ENANCIB Salvador, Bahia (2016).

$\mathrm{Na}$ BRAPCI foram recuperados 111 textos que tratavam do assunto, ao aplicar o recorte temporal 2006-2016 restaram 87 documentos, ao verificar se esses tratavam do assunto, foram excluídos 8 textos, dos quais: 2 eram resumos de tese, outros 2 eram textos repetidos e 4 tratavam de instituições e agências cujo nome e título da pesquisa tinha inovação. Ficou como amostra 79 documentos que foram analisados. No total, os trabalhos das duas bases somaram 121 textos que foram categorizados e analisados.

Foi aplicado o método analítico de conteúdo para a análise dos dados. Flick (2009) indica que esse método possibilita a formalização de categorias que facilitam a comparação e correlação entre os objetos estudados.

Para estruturar as categorias de análise, foram definidos critérios de classificação dos trabalhos com base na Lei brasileira de Inovação, que diz que inovação é a "Criação de

\footnotetext{
${ }^{4} \mathrm{O}$ termo "inovadora", também foi considerado, recuperando três textos. Cabe mencionar que foi feita a mesma busca no repositório "Questões em Rede" da UFF e obtivemos o mesmo resultado, 57 docs. Conferir em: $<$ http://repositorios.questoesemrede.uff.br/repositorios/>
} 
produtos, serviços ou processos - Inovação é a introdução de novidade ou aperfeiçoamento no ambiente produtivo ou social que resulte em novos produtos, processos ou serviços" (BRASIL, Lei 10.973, 2004). Os três: produto, processo e serviço foram as categorias selecionadas para verificar a correlação do tema das pesquisas analisadas. Com base nestas três categorias, definiu-se outras três subcategorias de classificação de aplicação de pesquisa:

a) Estudos conceituais: Pesquisas bibliográficas e documentais;

b) Estudos de mapeamento: Mapeia um ambiente, local ou população alvo;

c) Estudos de aplicação: Aplicação de um instrumento, ferramenta, modelo ou técnica

(de gestão, análise ou avaliação de serviço, produto ou processo).

Para categorizar os textos nos critérios definidos foram lidos os resumos, palavraschave e em vários casos o texto no todo, verificando a abordagem temática de cada um, por isso houve a necessidade de definir subcategorias de análise, para poder segmentar e analisar os dados. Os dados obtidos são apresentados na seção de dados e resultados.

\section{CIÊNCIA DA INFORMAÇÃO E SUAS APLICAÇÕES}

A Ciência da Informação está interligada com várias áreas do conhecimento, principalmente aquelas com o foco na informação e tecnologias, isso significa que o campo da área é amplo e interage, às vezes, diretamente e outras indiretamente com outros campos de conhecimento. O foco da Ciência da Informação "está preocupada com o corpo de conhecimentos relacionados à origem, coleção, organização, armazenamento, recuperação, interpretação, transmissão, transformação, e utilização da informação [...]” (BORKO, 1968, p. $01)$.

Ao estudar o objeto informação requer inúmeras variáveis de concepções, pois ainda não há uma definição unânime para "informação", para tanto na área da Ciência da Informação busca-se em cada aspecto relacionar a aplicação da informação com uma finalidade, ou, a um campo ou objeto específico, como estudar cada peça do quebra cabeça de forma separada.

Saracevic (1999, p. 03) enfatiza as características da Ciência da Informação pela: a) interdisciplinaridade, b) conexão com as tecnologias da comunicação e informação, c) participação ativa no desenvolvimento da sociedade da informação. 
Veiga-Almeida, Fernández-Molina e Linares (2009, p. 09) assinalam que "A Ciênica da Informação como campo de prática profissional e investigação científica, a disciplina enfoca os problemas de comunicação efetiva dos registros do conhecimento entre humanos e o contexto das organizações sociais, assim como as necessidades e usos da informação pelos indivíduos".

Para Araújo (2009, p. 200) “'A informação é definida enquanto algo independente dos sujeitos, do contexto histórico-cultural, passível de ser estudada objetivamente, medida, e ser compreendida por meio de leis e regularidades".

Mediante as conjunturas da área, essa pesquisa se baseia no paradigma social e cognitivo, de acordo com e Veiga-Almeida, Fernández-Molina e Linares (2009, p. 12), “o paradigma cognitivo se destaca por expressar e refletir em uma troca social e intelectual mais radical, e centrar-se no sujeito como ente individual" aqui enfatiza-se a informação estratégica, em CT\&I, como necessária para o desenvolvimento de serviços e produtos para diversos campos de conhecimento.

Araújo (2010) em seu estudo faz a análise do uso de ambos os modelos conceituais: físico, cognitivo e social, considerando que um não substitui o outro. Aponta cinco campos de aplicação dos modelos e cada um tem uma finalidade. No quadro 1 está exposto o exemplo dado pelo autor para o campo de Produção e comunicação da informação em CT\&I.

Quadro 1 - aplicação da informação nos modelos: físico, cognitivo e social.

\begin{tabular}{|l|l|}
\hline \multicolumn{2}{|c|}{ Produção e comunicação da informação em CT\&I } \\
\hline Modelo Físico & $\begin{array}{l}\text { Identificação das características das fontes formais e informais, temporalidade dos } \\
\text { produtos informacionais. }\end{array}$ \\
\hline Modelo Cognitivo & Estudo dos gatekeepers e colégios invisíveis. \\
\hline Modelo Social & $\begin{array}{l}\text { Estudo das redes formadas na produção do conhecimento científico; estratégias de } \\
\text { colaboração. }\end{array}$ \\
\hline
\end{tabular}

Fonte: Adaptação do quadro de Araújo (2010, p. 103, grifo nosso).

Os estudos aos moldes cognitivo e social visam a informação e o sujeito como elemento participante no processo de desenvolvimento do conhecimento, relacionando-se entre si. Matheus (2005) indica que as pesquisas devem seguir programas de estudos que de preferência sejam interdisciplinares, interagindo conhecimentos de visão e conhecimentos de áreas correlatas para melhor aplicação e solução de problemas.

\footnotetext{
${ }^{5}$ Neste estudo utilizamos o conceito de informação de Araújo $(2009,2010)$, baseado na ideia do "comportamento e as propriedades da informação".
} 
É aí que o estudo da produção científica sobre inovação entra, justifica-se por ser um processo que envolve métodos, produtos e serviços informacionais, com aplicação de informações específicas, atualizadas e confiáveis. Borko (1968, p. 05) menciona que a CI deve investigar "as propriedades e comportamento da informação, as forças que governam os fluxos e os usos da informação, e as técnicas, tanto manual quanto mecânica, de processamento da informação, visando sua armazenagem, recuperação, e disseminação ideal". Independente da área de aplicação.

Sugahara e Jannuzzi (2005) relatam em seus estudos a relevância das pesquisas com foco na inovação, principalmente ao que tange as fontes informacionais, já que para inovar é preciso que haja aplicação de fontes confiáveis e específicas para a CT\&I. No caso do Brasil é uma área com pouca investigação sob a ótica dessa abordagem. As autoras enfatizam que faltam estudos que ajudem a mapear e caracterizar fontes relevantes para o processo de inovação, já que esse ambiente é constantemente mutável e vulnerável ao meio, principalmente com a internet. Eis uma carência latente de estudos aplicados à CI.

A visão de Borko (1968), exposta anteriormente, norteia esse estudo, pois com base em suas afirmações é possível investigar a produção científica da área com foco na inovação. Muitos autores como Pedro Demo (2000), Capuro e Hjorland (2003), Araújo (2003, 2009, 2010, 2014a, 2014b) destacam a importância de estudos e das tendências na definição e produção científica da área, assim como na definição enquanto campo de concentração.

\subsection{INFORMAÇÃO COMO BASE PARA O DESENVOLVIMENTO E INOVAÇÃO}

Informação é algo intangível, a não ser que esteja associada ou fixada a um suporte, em seu estado construtivo não pode ser mensurado ou medido. Araújo (2010, p.97) aponta que a “Informação é uma construção (algo é informativo num momento, em outro já não é mais; tem relevância para um grupo, mas não para outro; e assim sucessivamente), é uma construção conjunta, coletiva - ou melhor, intersubjetiva". Sem informação não há conhecimento, nem desenvolvimento, uma coisa está interligada a outra.

Para adquirir conhecimento e propiciar desenvolvimento, independente da área, se faz necessário o acesso à informação relevante e atual. $\mathrm{O}$ desenvolvimento científico e tecnológico torna-se fundamental, e a informação passa a ser o contexto da qualidade (ARAÚJO, 2009). Seja qual for a fonte a informação, tem desempenhado importante papel na sociedade moderna. 
Gómez, Salazar e Vargas (2016) ressaltam que o uso de fontes de informação como determinante para a geração de produtos e processos de inovação, destaca a função de fontes úteis de informação aplicadas para a inovação. O atributo mais importante, na atualidade, é a produção de conhecimento de qualidade, focado no processo de "aproximação entre a ciência e a indústria estabelecendo a importância da informação para a competitividade nas empresas" (HENRIQUE, 2006, p. 37).

Para que a informação sirva de base para o desenvolvimento é preciso o "reconhecimento governamental da importância estratégica da ciência e tecnologia, como processo de transferência da informação, como parte inseparável da investigação e desenvolvimento" (SARACEVIC, 1999, p. 1053, tradução dos autores); seja em investimentos ou subsídios para o acesso, publicação e disseminação de novas informações, tornando o ciclo informativo mais ágil e dinâmico em todos os aspectos do processo.

No Brasil a produção de informação e conhecimento, direcionados para o desenvolvimento, são tratados na legislação como "propriedade intelectual”, a lei n. 13.243 de 2016, art. 15-A, cap. V e VII, dispõe sobre estímulos ao desenvolvimento científico, à pesquisa, à capacitação científica e tecnológica e à inovação. Menciona no Caput V sobre a "gestão da propriedade intelectual e de transferência de tecnologia", no qual fala do conhecimento científico e da informação no ciclo inovativo. Assim como enfatiza no Caput VII que o desenvolvimento científico serve "Para orientação das ações institucionais de capacitação de recursos humanos em empreendedorismo, gestão da inovação, transferência de tecnologia e propriedade intelectual" (BRASIL, 2016, grifo nosso).

É de responsabilidade de cada país criar estruturas legais, financeiras e educacionais que sirvam de suporte para o desenvolvimento interno e externo de seu país. Borges e Carvalho (1998, p. 77) indicam que existem “[...] os serviços de informação voltados para o provimento de empresas e indústrias existentes no Brasil, o qual apresenta competência e forte potencial para atuar na área de informação para negócios". No entanto ainda são serviços informacionais embrionários, escassos, porém é uma área promissora, o que temos não se compara aos serviços disponíveis no mercado internacional, como as duas grandes bases Gale Cengage e ProQuest ${ }^{6}$, especializadas em organizar e comercializar informação estratégica para o mundo todo.

\footnotetext{
${ }^{6}$ Gale Cengage <http://www.gale.cengage.com/DirectoryLibrary/available.htm>. ProQuest $<$ http://www.proquest.com/>
} 
É sabido que, para que haja desenvolvimento é preciso ter acesso irrestrito à informação, o mercado necessita saber o que está sendo produzido de novo, sejam produtos ou processos; as ferramentas de tecnologias de informação e comunicação (TIC) têm sido bastante utilizadas, por facilitarem o processo de obtenção de informação. Segundo Baller, Dutta e Lanvin (2016), elas são a espinha dorsal da quarta revolução industrial, o futuro dos países, empresas e indivíduos dependerão mais das tecnologias digitais do que qualquer outra coisa, principalmente as informacionais.

O sistema econômico e tecnológico é movido pelo capitalismo informacional ${ }^{7}$, uma vez que se produz porque sabe ou aprende, nesse sentido a informação se tornou "o único recurso realmente controlador, o fator de produção absolutamente decisivo" (DRUCKER, 1999, p. 15), seja em esfera global ou local.

Parrilli e Heras (2016) salientam em seu estudo a ampla aplicação de fontes informacionais científicas e tecnológicas para a geração de conhecimento no mercado competidor, e, o uso dos recursos informacionais no processo de inovação e desenvolvimento de empresas. Sugahara e Jannuzzi (2005, p. 45) expressam que, "O uso de fontes de informação internas e externas à empresa para a geração da inovação tecnológica é fator determinante para a competitividade de qualquer economia".

É por esses motivos que a informação é extremamente importante, pois movimenta o mundo, as pessoas, a sociedade, as empresas, os países. Corporações necessitam de informação, é o recurso fundamental para a sua sobrevivência. Informação corriqueira existe por toda parte, no entanto, a indústria inserida em um mercado necessita de fontes informacionais confiáveis e de credibilidade, e esse tipo de informação, na grande maioria é comercial, e que, em alguns casos, não estão organizadas em bases, plataformas específicas a fim de propiciar o fácil acesso.

\subsection{CIÊNCIA, TECNOLOGIA E INOVAÇÃO NO BRASIL: CENÁRIO 2016-2019}

Segundo Cavalcante (2016), um país para ser competitivo precisa ter investimento em: ciência, tecnologia e inovação, profissionais qualificados, estratégias de desenvolvimento adequadas ao país, produtividade científica e representativa de qualidade.

\footnotetext{
${ }^{7}$ Usa-se o termo "Capitalismo informacional" com base nas mudanças sociais e cognitivas advindas do uso e aplicação da informação. Ver mais em: CASTELLS, Manuel. A Sociedade em Rede. São Paulo: Paz e Terra, 2006.
} 
O presidente da Financiadora de Estudos e Projetos-FINEP, em 2012 revelou que, "a maioria dos pesquisadores brasileiros (57\%) trabalham nas universidades, (37\%) estão nas empresas e (5\%) no governo. Nos EUA o resultado é o oposto, (79\%) estão nas empresas, (14\%) nas universidades e (3,6\%) estão no governo" (ARBIX, 2012). Este cenário mostra que o fator impactante no Brasil está nas estratégias de desenvolvimento, em que, a maior parte dos pesquisadores estão no serviço público e não no mercado e indústrias, onde realmente carece de estudos e pesquisas focadas para a inovação e competitividade. Sendo assim, as organizações dependem estritamente do conhecimento técnico/científico das universidades para que haja desenvolvimento.

No Brasil as organizações com maior índice de investimento e inovação em tecnologia são as estatais: Petrobrás, Eletrobrás, Embraer, Vale, empresas de telecomunicações. Por volta de 7 a 10 mil empresas que representam o total desse investimento, que somam cerca de $0,5 \%$ do PIB, 600 a 700 delas respondem à 90\% desse total, entretanto, a maior parte delas são estrangeiras (ARBIX, 2012).

O relatório da UNESCO (2015, p.228) alerta, “a indústria brasileira deve abraçar a inovação para permanecer competitiva internacionalmente". O mesmo relatório expõe que a publicação científica do país ficou em $13^{\circ}$ lugar, com baixo índice de citação e registros de patente, demonstrando a necessidade de investimento em melhorias na educação e incentivo em desenvolvimento interno, de forma que possa realmente ser competitivo e citado internacionalmente. Carece de políticas públicas forte e permanente, com foco na educação e publicação científica em todas as fases de ensino no país.

No relatório do IMD-Word Competitiveness Ranking (2018) a classificação do Brasil ficou em $60^{\circ}$ lugar no ranking de competitividade, abaixo do Perú, Argentina, México, Índia, Chile, entre outros, em 2013 ficou no $46^{\circ}$ lugar, despencando de posição.

Recentemente foi aprovada a lei n. 13.243 de 12 de janeiro de 2016, que dispõem sobre estímulos ao desenvolvimento científico, à pesquisa, à capacitação científica e tecnológica e à inovação, para que sejam feitos constantes investimentos em pesquisas para a tomada de decisões.

O Brasil declara nas diretrizes estratégicas de desenvolvimento no Plano Plurianual de 2016-2019, os incentivos para a "Promoção da Ciência, da Tecnologia e da Inovação e estímulo ao desenvolvimento produtivo, com ampliação da produtividade, da competitividade e da sustentabilidade da economia" (BRASIL, 2015, p. 161), como principal foco, o fomento de inovação interna. 
O Ministério da Ciência, Tecnologia e Informação - MCTI tem o papel de impulsionar a economia brasileira, "apoiando os setores portadores de futuro, preparando o Brasil para a economia do conhecimento e da informação, auxiliando na transição para uma economia verde e criativa e contribuindo para a inclusão produtiva e social” (MCTI, 2011, p. 96).

As análises e dados sobre o desenvolvimento do país, principalmente em C\&T, evidenciam a necessidade de forte investimento em capacitação interna para que o país realmente cresça. O governo deve projetar seus esforços na formação de doutores, investimento em pesquisas, estimular a produtividade científica de qualidade, de alto impacto e em outras línguas, são medidas que mensuram o fator chave de inovação e competitividade de um país, procedimentos necessários para alcançar a meta nos próximos anos (IMD-Word, 2018). Mas a recessão da economia brasileira, que se agravou em 2019, passa por contingenciamento/corte de verbas, entre as áreas afetadas está a Educação, em todas as fases de formação do individuo, ao invés de investimentos o governo atual optou pela redução dos recursos.

Para tanto, entende-se que as redes e estruturas informacionais especializadas são caminhos para a organização de informação e, o desenvolvimento de conhecimento científico e estratégico, auxiliando empresas, organismos e o próprio governo no empreendimento de esforços em busca da inovação, possibilitando a obtenção de dados e informação subsidiária para a almejada competitividade.

\section{DADOS E RESULTADOS}

Nesta seção são apresentados os dados coletados na página da ANCIB e BRAPCI nos anos de 2006-2016. A análise segui com duas divisões na apresentação: a primeira apresenta a característica da amostra, e a segunda a categorização dos dados.

\subsection{CARACTERÍSTICAS DA AMOSTRA}

No ENANCIB, a amostra de 42 trabalhos representa 1,4\% do total 2.797 textos publicações no período do recorte. Para especificar os anais do ENANCIB optou-se pela numeração romana, sendo VII para o ano de 2006 e XVII para o ano 2016.

Quadro 2 - Publicações do ENANCIB (2006-2016)

\begin{tabular}{|c|c|c|c|c|c|c|c|c|c|c|c|c|}
\hline \multicolumn{13}{|c|}{ ENANCIB } \\
\hline GRUPOS & VII & VIII & IX & $\mathbf{X}$ & XI & XII & XIII & XIV & XV & XVI & XVII & SOMA \\
\hline GT1 & 14 & 20 & 21 & 17 & 20 & 23 & 28 & 25 & 20 & 18 & 29 & 235 \\
\hline
\end{tabular}




\begin{tabular}{|c|c|c|c|c|c|c|c|c|c|c|c|c|}
\hline GT2 & 23 & 46 & 23 & 29 & 29 & 35 & 28 & 40 & 54 & 36 & 61 & 404 \\
\hline GT3 & 21 & 27 & 20 & 20 & 19 & 24 & 34 & 32 & 24 & 25 & 29 & 275 \\
\hline GT4 & 19 & 23 & 16 & 10 & 42 & 24 & 24 & 33 & 37 & 40 & 45 & 313 \\
\hline GT5 & 11 & 17 & 23 & 23 & 21 & 26 & 31 & 25 & 32 & 24 & 23 & 256 \\
\hline GT6 & 7 & 8 & 17 & 13 & 21 & 16 & 21 & 18 & 25 & 16 & 22 & 184 \\
\hline GT7 & 12 & 29 & 14 & 11 & 25 & 28 & 30 & 37 & 41 & 29 & 48 & 326 \\
\hline GT8 & 0 & 0 & 16 & 20 & 27 & 22 & 30 & 40 & 37 & 32 & 43 & 267 \\
\hline GT9 & 0 & 17 & 0 & 15 & 12 & 17 & 22 & 19 & 23 & 22 & 20 & 167 \\
& mus. & & & & & & & & & & \\
\hline GT10 & 0 & 0 & 0 & 0 & 36 & 34 & 38 & 27 & 35 & 37 & 53 & 260 \\
\hline GT11 & 0 & 0 & 0 & 0 & 13 & 23 & 20 & 15 & 20 & 19 & 110 \\
\hline \multicolumn{19}{|c|}{ TOTAL DE PUBLICAÇÕES } \\
\hline
\end{tabular}

Fonte: Dados da pesquisa (2017)

Os 79 artigos encontrados na BRAPCI representam $0,46 \%$ do total de 16.826 textos publicações na base, isso no período da coleta. Ver o detalhamento da amostra no quadro 3.

Quadro 3 - Publicações da BRAPCI (2006-2016)

\begin{tabular}{|c|c|c|}
\hline ANO & PERIÓDICOS & QUT. \\
\hline $2009,2011,2012,2013,2014,2016=6$ & Perspectivas em Ciência da Informação & 8 \\
\hline $2006,2007,2008,2011,2013,2015=6$ & DataGramaZero & 12 \\
\hline $2006,2007,2009,2012,2015,2016=6$ & Informação \& Informação & 9 \\
\hline $2012,2013,2014,2015,2016=\mathbf{5}$ & Perspectivas em Gestão \& Conhecimento & 9 \\
\hline $2007,2008,2009,2011,2013=\mathbf{5}$ & $\begin{array}{l}\text { Revista Eletrônica de Comunicação, Informação \& Inovação } \\
\text { em Saúde }\end{array}$ & 7 \\
\hline $2007,2010,2012,2014=4$ & Liinc em revista - IBICT & 11 \\
\hline $2008,2010,2014=3$ & $\begin{array}{l}\text { Encontros Bibli: Revista Eletrônica de Biblioteconomia e } \\
\text { Ciência da Informação }\end{array}$ & 3 \\
\hline $2008,2015,2016=3$ & Informação \& Sociedade: Estudos & 3 \\
\hline $2011,2012=2$ & Revista Digital de Biblioteconomia \& Ciência da Informação & 2 \\
\hline 2015 & InCID: Revista de Ciência da Informação e Documentação & 2 \\
\hline 2016 & Revista P2P e INOVAÇÃO & 1 \\
\hline 2016 & Revista Brasileira de Educação em Ciência da Informação & 1 \\
\hline 2014 & Informação Arquivística & 1 \\
\hline 2013 & Em Questão & 1 \\
\hline 2013 & informação@profissões & 1 \\
\hline 2012 & Inclusão Social - IBICT & 1 \\
\hline 2012 & $\begin{array}{l}\text { BIBLOS - Revista do Instituto de Ciências Humanas e da } \\
\text { Informação }\end{array}$ & 1 \\
\hline 2012 & Biblionline & 1 \\
\hline 2011 & Ponto de Acesso & 1 \\
\hline 2009 & Revista ACB: Biblioteconomia em Santa Catarina & 1 \\
\hline 2008 & Revista Brasileira de Biblioteconomia e Documentação & 1 \\
\hline 2007 & ETD - Educação Temática Digital & 1 \\
\hline 2007 & Transinformação & 1 \\
\hline 10 ANOS & 23 PERIÓDICOS & 79 \\
\hline
\end{tabular}

Fonte: Dados da pesquisa (2017)

$\mathrm{Na}$ amostra extraída da BRAPCI é possível perceber que, seis revistas foram as que mais publicaram sobre o tema, destas, também as que tinham maior aparição em variados anos: 3 revistas publicaram em 6 anos distintos, outras 2 em 5 anos, e, 1 em 4 anos diferentes. 


\section{INOVAÇão}

A seguir, são apresentados os dados sobre os grupos de trabalho e periódicos onde houve publicações.

Uma questão importante a ser mencionada é que, o ENANCIB é um evento exclusivo da CI, se organiza por temáticas, cada GT é um grupo de trabalho que concentra as suas pesquisas em determinados assuntos, mas alguns GTs específicos apresentaram pesquisas sobre o tema. Cabe salientar que o nome dos GT'S mudou ao longo dos anos.

Quadro 4 - Período e GTs das publicações do ENANCIB

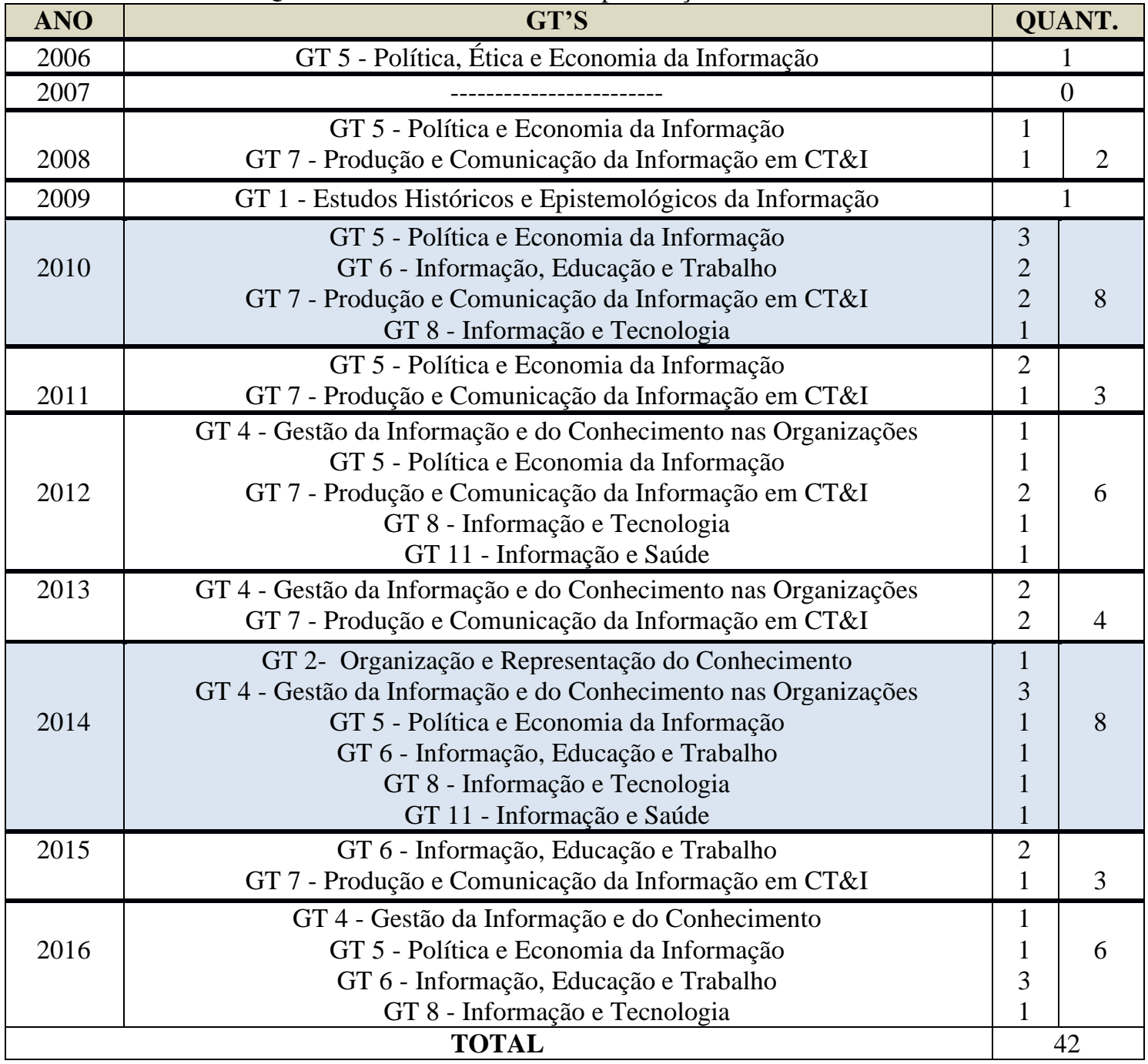

Fonte: elaborado pela autora (2017)

$\mathrm{Na}$ análise do quadro 4 os anos de maior concentração de pesquisas com a temática foram em 2010 e 2014. De 11 grupos de trabalho, 8 deles publicaram sobre o tema, no entanto, a concentração maior ficou nos quatro grupos: GT 5 e 7, cada um com dez publicações cada, o 6 e 4, com oito e sete publicações cada, 35 trabalhos que representam $83 \%$ de todas as publicações do total da amostra. 
Quanto a autoria das publicações, os 121 trabalhos analisados são de autoria de 220 pesquisadores. Destes, 11 publicam trabalhos tanto no ENANCIB quanto nos periódicos indexados na BRAPCI.

Quadro 5 - Autor versus publicação

\begin{tabular}{|c|c|c|c|}
\hline BRAPCI - 153 - AUTORES & N. & ENANCIB - 67 - AUTORES & N. \\
\hline Carlos José Saldanha Machado & 2 & Antonio Wagner Chacon Silva & 2 \\
\hline Celeste Aída Sirotheau Corréia Jannuzzi & 2 & Clóvis Montenegro de Lima & 2 \\
\hline Clóvis Ricardo Montenegro de Lima & 4 & Dayanne da Silva Prudencio & 2 \\
\hline Fernando Augusto Mansor de Mattos & 2 & Elaine da Silva & 3 \\
\hline Gertrudes Aparecida Dandolini & 2 & Gregorio Varvakis & 2 \\
\hline Helena Maria Martins Lastres & 2 & Jefferson Veras Nunes & 2 \\
\hline Ilse Maria Beuren & 2 & Liz-Rejane Issberner & 3 \\
\hline João Artur de Souza & 2 & Mara Eliane Fonseca Rodrigues & 3 \\
\hline Jordan Paulesky Juliani & 2 & Maria José Vicentini Jorente & 2 \\
\hline Jorge Tadeu de Ramos Neves & 2 & Marianna Zattar & 2 \\
\hline José Eduardo Cassiolato & 2 & Marta Lígia Pomim Valentim & 3 \\
\hline Lidiane dos Santos Carvalho & 3 & Nanci Oddone & 3 \\
\hline Marcello Cavalcanti Barra & 2 & Sarita Albagli & 2 \\
\hline Marcelo Seido Nagano & 2 & Stella Moreira Dourado & 3 \\
\hline Maria Celeste Reis Lobo de Vasconcelos & 2 & & $\mathbf{3 4}$ \\
\hline Maria Inês Tomaél & 3 & & \\
\hline Maria José Vicentini Jorente & 2 & & \\
\hline Natalia Nakano & 2 & & $45+34=79$ \\
\hline Thais Batista Zaninelli & 3 & & \\
\hline Thais Elaine Vick & 2 & & \\
\hline 20 autores & $\mathbf{4 5}$ & & \\
\hline
\end{tabular}

A cor azul indica autores que tiveram publicações nas duas fontes.

A cor rosa indica autores que detiveram maiores números de publicações.

Fonte: Dados da pesquisa (2017)

Nas duas amostras, os autores que mais publicaram sobre o assunto somam 34 (de 2 a 4 artigos por autor), igual a 15,45\% do total de 220 autores. Já as publicações destes 34 autores representam 65,2 \% do total de 121 textos. Do total de 220 autores, apenas 29 publicam sozinhos os demais 191 publicaram em coautoria de 2, 3, 4, 5 e até 6 autores.

Os dados apontam para a maioria das publicações, sobre o tema objeto do estudo, na Ciência da Informação são feitas em co-autoria e que os periódicos são mais visados que o evento ENANCIB, possivelmente pela amplitude de periodicidade e títulos, pois o evento ENANCIB acontece uma vez por ano e há a necessidade do deslocamento do pesquisador e custos adicionais como a inscrição, anuidade e demais despesas. No entanto, as publicações em periódicos têm periodicidade variada, e a maioria utilizam plataformas de submissão online e sem custos para submissão além de possuírem elevado fator de impacto. 
Na etapa de análise, foi usada na a categorização dos trabalhos a classificação obtida na lei 10.973 de 2004, que trata sobre inovação, pesquisa científica e tecnológica, na qual classifica inovação em três categorias de aplicação: produto, processo e serviço. Com isso analisou-se quais termos eram mais enaltecidos nos trabalhos, executando a leitura dos 121 textos. Ver o quadro 6.

Quadro 6 - Classificação das pesquisas

\begin{tabular}{|c|c|c|}
\hline SUBCLASSIFICAÇ̃̃̃O & ENANCIB & BRAPCI \\
\hline Produto & 1 & 8 \\
\hline Processo & 37 & 60 \\
\hline Serviço & 1 & 11 \\
\hline Outros & 3 & - \\
\hline
\end{tabular}

Fonte: Dados da pesquisa (2017)

Os dados tabulados sobre os 121 trabalhos analisados, nove deles indicam estudos sobre produtos inovativos. Na área da Ciênica da Informação os estudos sobre o processo de inovação assumem o lugar de destaque, representando 80\%, com 97 pesquisas. E 12 estudos se preocupavam com os estudos dos serviços considerados inovativos. Houve três publicações que não se encaixaram em nenhum dos critérios definidos. $\mathrm{O}$ quadro oito expõe as temáticas relacionadas ao objeto do estudo.

Quadro 7- Temáticas empregadas ao tema trabalhado no texto

\begin{tabular}{|l|c|}
\hline \multicolumn{1}{|c|}{ TERMOS RELACIONADOS } & FREQUÊNCIA \\
\hline Ensino e aprendizagem & 4 \\
\hline Gestão da informação e do conhecimento para inovação & $16-13,2 \%$ \\
\hline Informação como fonte para a tomada de decisões & $25-20,6 \%$ \\
\hline Inovação nas práticas de ensino e curricular & 4 \\
\hline Inovação na produção de informacional e publicação científica & $13-10,7 \%$ \\
\hline $\begin{array}{l}\text { Mapeamento de estudos sobre o tema e suas derivações (inovação aberta, radical, } \\
\text { social, incremental) }\end{array}$ & $15-12,3 \%$ \\
\hline Aplicação de ferramentas & 5 \\
\hline Inovação em unidades de informação & 6 \\
\hline Inovação na área da saúde & 7 \\
\hline Atuacão profissional no processo da inovação & 1 \\
\hline Produção do conhecimento no processo de inovação & 6 \\
\hline Inovação do conceito & 1 \\
\hline Inovação na aplicação de técnicas & 4 \\
\hline Evolução do processo de inovação & 4 \\
\hline Indicadores de desenvolvimento & 4 \\
\hline Indicadores de inovação & 2 \\
\hline Aprendizagem e inovação na indústria farmacêutica & 1 \\
\hline Inovação na agricultura & 3 \\
\hline
\end{tabular}

Fonte: Dados da pesquisa (2017)

Percebeu-se que na maior parte das pesquisas analisadas o enfoque é direcionado ao processo, enquanto $20,6 \%$ dos assuntos trata da informação como fonte para a tomada de decisões no processo de inovação, assim como a gestão da informação e do conhecimento no 
processo inovativo, mapeamento das derivações de inovação, na produção de informação e publicação científica, esses quatro temas somam ao todo 50,7\% dos temas trabalhados na área. Os tipos de pesquisadas realizadas são apresentadas como subclassificação, disponível no quadro 8.

Quadro 8 - Subclassificação das pesquisas

\begin{tabular}{|l|c|c|}
\hline \multicolumn{1}{|c|}{ SUBCLASSIFICAÇÃ̃ } & ENANCIB & BRAPCI \\
\hline Estudos de aplicação & 8 & 2 \\
\hline Estudos conceituais & 10 & 39 \\
\hline Estudos de mapeamento & 22 & 33 \\
\hline Misto: Conceitual e mapeamento & - & 4 \\
\hline Nenhuma das opções & 2 & 1 \\
\hline
\end{tabular}

Fonte: Dados da pesquisa (2017)

$\mathrm{Na}$ maioria dos trabalhos, a pesquisa conceitual e de mapeamento, representaram $85,9 \%$, dos estudos. Os que são relacionados a aplicação de processos inovativos na Ciênica da Informação mostraram pouca expressividade, apenas 10 , cerca de $1 \%$.

Em geral, as pesquisas estudam o processo e usos, a gestão da informação e conhecimento como forma ou produto para promover a inovação, estão mais atreladas as sondagens e ao ambiente, usuários, necessidades e processos.

Pesquisas conceituais trazem ideias, significados, visões e discussões sobre a aplicação da informação no processo de inovação, assim como usos e adaptações de ferramentas de gestão, validação e certificação de processos, serviços ou produtos considerados inovativos.

Geralmente estão atreladas a processos e sistemas que diferem do fazer profissional da área, como o caso das pesquisas que destacaram a publicação de e-books em sites das editoras universitárias, consideradas inovadoras. Outras pesquisas destacam a importância e relevância da informação no fluxo e processo de inovação nos diversos segmentos da sociedade.

\section{CONCLUSÕES}

A pesquisa buscou conhecer o cenário das publicações científicas brasileiras sobre estudos que abordam a temática inovação, publicadas em canais formais de comunicação da Ciência da Informação.

Os dados identificaram que a Ciênica da Informação se preocupa com o objeto informação no processo de inovação, como elemento propulsor, fonte de dados que ajuda no desenvolvimento dos insumos inovativos nas diversas áreas de aplicação. Tais resultados são 
compatíveis com a visão de Borko (1968), uma vez que a considera aflita em solucionar problemas oriundos da informação a serviço da sociedade.

As pesquisas destinadas a análise e aplicação de inovação, se dedicam aos estudos de casos, usando de recursos e aplicação para áreas específicas do conhecimento: saúde, agricultura, tecnologia, entre outros estudos realizam mapeamentos, mensurações, avaliam a informação no processo de inovação ou certificação de produtos ou serviços.

A Ciênica da Informação é uma área ampla, transdisciplinar, inter e multidisciplinar e desta maneira objetiva estudar a diversidade de problemas que necessitam de solução, os estudos sobre inovação, no caso do ENANCIB - 2.797 documentos e na BRAPCI - 16.826 artigos, demonstraram incipiência e ainda necessitam de aprofundamento e desdobramentos, pois o tema representa $0,61 \%$ de todas as publicações do evento e da base, os quais foram objeto do presente estudo.

A presente pesquisa não teve a intenção de analisar a qualidade, profundidade, divergências ou controvérsias da abordagem da temática na área, e sim sondar os cenários e enfoque dos estudos da Ciência da Informação sob a ótica do tema Inovação.

Houve várias limitações: no ENANCIB há várias publicações em formato de pôster (11 resumos) que são publicações sucintas, contêm poucos dados para serem analisados. Oito textos indicavam que a pesquisa estava em andamento ou era uma parcial de um projeto maior, geralmente de mestrado ou doutorado, característicos de um evento de classe, mas esses fragmentos não possibilitam compor uma análise para esse tipo de estudo.

Outro aspecto refere-se ao formato do arquivo digital, pois algumas publicações estão em PDF formato de imagem, esse formato dificulta a recuperação de qualquer dado a ser minerado no documento. Toda coleta, levantamento, tabulação e análise precisaram serem realizadas manualmente, uma por uma, demandando tempo, energia e dedicação para executálas.

Quanto as publicações da BRAPCI, entre as dificuldades foram as revistas que deixaram de publicar ou não estão acessíveis no fim de semana, possivelmente porque a instituição desliga o servidor ou roteador da internet. Outra questão derivou da própria base, em meados de outubro de 2017 iniciou uma atualização em seu sistema, apresentando neste período diversas falhas no funcionamento, o qual não permitiu fazer buscas específicas e da expedição de relatórios.

Em geral, a Ciência da informação está interessada em resolver os problemas tecnológicos e informacionais, no entanto, os próprios canais de comunicação formais não são estruturados para que possibilite realizar a mineração de dados de forma eficiente uma 
pesquisa que empenhe muitos dados, carecendo de reflexão e discussão sobre os fazeres científicos e práticos da área.

\section{REFERENCIAS}

ANCIB - Associação Nacional de Pesquisa e Pós-Graduação em Ciência da Informação. Anais ENANCIB. 2017.

ARBIX, Glauco. Investimento em inovação: FINEP e os pesquisadores brasileiros. Jornal em discussão, Senado, Brasília, 07 nov. 2012. Disponível em:

http://www.senado.gov.br/noticias/Jornal/emdiscussao/inovacao/investimento-inovacaotecnologica-finep-pesquisadores-brasil.aspx. Acesso em: 24 jun. 2018.

ARAÚJO, Carlos Alberto Ávila. A ciência da informação como ciência social. Ciência da Informação, Brasília, v. 32, n. 3, p. 21-27, set./dez. 2003.

ARAÚJO, Carlos Alberto Ávila. Correntes teóricas da ciência da informação. Ciência da Informação, Brasília, DF, v. 38, n. 3, p.192-204, set./dez. 2009.

ARAÚJO, Carlos Alberto Ávila. O conceito de informação na Ciência da informação. Informação \& Sociedade: Estudos, João Pessoa, v.20, n.3, p. 95-105, set./dez. 2010.

ARAÚJO, Carlos Alberto Ávila. O que é ciência da informação? Informação e Informação, Londrina, v. 19, n. 1, p. $01-30$, jan./abr. 2014a.

ARAÚJO, Carlos Alberto Ávila. Fundamentos da Ciência da Informação: correntes teóricas e o conceito de informação. Perspectivas em Gestão \& Conhecimento, João Pessoa, v. 4, n. 1, p. 57-79, jan./jun. 2014b.

BALLER, Silja; DUTTA, Soumitra; LANVIN, Bruno (ed.). The Global Information Technology Report 2016: Innovating in the Digital Economy. Word Economic Forum: INSEAD: University Johnson, 2016. Disponível em: http://www3.weforum.org/docs/GITR2016/WEF_GITR_Full_Report.pdf. Acesso em: 15 maio 2018.

BRAPCI - Base de dados de Periódicos em Ciência da Informação. 2017. Disponível em: http://www.brapci.ufpr.br/brapci/index.php/home. Acesso em: 26 jan. 2018.

BORKO, H. Information science: what is it? American Documentation, v.19, n.1, p. 3-5, 1968.

BORGES, Mônica Erichsen Nassif; CARVALHO, Natália Guiné de Mello. Produtos e serviços de informação para negócios no Brasil: características. Ciência da Informação, Brasília, v. 27, n.1, p.76-81, jan./abr. 1998.

BRASIL. PPA-Plano Plurianual 2016-2019: Desenvolvimento, Produtividade e Inclusão Social. Brasília: Ministério do Planejamento, Orçamento e Gestão: Secretaria de Planejamento e Investimento Estratégico. 2015. Disponível em: 
http://www.planejamento.gov.br/secretarias/upload/arquivo/spi-1/ppa-2016-2019/ppa-20162019-ascom-3.pdf. Acesso em: 09 fev. 2018.

BRASIL. Lei n. 13.243 de 11 de janeiro de 2016. Dispõe sobre estímulos ao desenvolvimento científico, à pesquisa, à capacitação científica e tecnológica e à inovação. Diário Oficial [da] União, Brasília, DF, 12 jan. 2016.

CAPURRO, R.; HJORLAND, B. The concept of information. Annual Review of Information science and Technology, v. 37, p. 343-411, 2003.

CAVALCANTI, Marcos. Inovação, ciência e tecnologia a persistência no erro. Inteligência Empresarial, Rio de Janeiro, 31 maio, 2016. Disponível em: http://crieinteligenciaempresarial.blogspot.com.br/2016/05/inovacao-ciencia-e-tecnologia.html. Acesso em: 02 jun. 2018.

DEMO, Pedro. Metodologia do conhecimento científico. São Paulo: Editora Atlas. 2000. 2016p.

DRUCKER, Peter F. Sociedade pós-capitalista. São Paulo: Editora Pioneira, 1999.

ENANCIB - Encontro Nacional de Pesquisa em Ciência da Informação. 16, 2015. Anais do ENANCIB, João Pessoa, PB, 2015. Disponível em:

http://www.ufpb.br/evento/lti/ocs/index.php/enancib2015/enancib2015/schedConf/presentatio ns. Acesso em: 12 dez. 2017.

ENANCIB - Encontro Nacional de Pesquisa em Ciência da Informação. 17, 2016. Anais do ENANCIB, Salvador, Bahia, 2016. Disponível em:

http://www.ufpb.br/evento/lti/ocs/index.php/enancib2016/enancib2016/schedConf/presentatio ns. Acesso em: 12 dez. 2017.

FLICK, Uwe. Introdução à pesquisa qualitativa. Tradução de Joice Elias Costa. 3.ed. São Paulo: Artmed. 2009.

GÓMEZ, Jaime; SALAZAR, Idana; VARGAS, Pilar. Sources of Information as Determinants of Product and Process Innovation. PLOS ONE, Califórnia, v.11, n. 4, abr. 2016.

HENRIQUE, Luiz Cláudio Junqueira. Inovação e informação. 2006. 225 f. Tese (Doutorado em Ciência da Informação) - Escola de Ciência da Informação, Universidade Federal de Minas Gerais. Belo Horizonte, 2006.

IMD- WORLD COMPETITIVENES SCENTER. Ranking 2018. 2018. Disponível em: https://www.imd.org/wcc/world-competitiveness-center-rankings/world-digitalcompetitiveness-rankings-2018/. Acesso em: 15 jul. 2018.

LANDRY, Maurice. A Note on the concepto 'Problem'. Sage Journal, [s. 1.], v. 16, n. 2, p. 315-343, mar. 1995. DOI: https://doi.org/10.1177/017084069501600206

MATHEUS, Renato Fabiano. Rafael Capurro e a filosofia da informação: abordagens, conceitos e metodologias de pesquisa para a Ciência da Informação. Perspectivas em Ciência da Informação, Belo Horizonte, v. 10, n. 2, p. 140-16, maio, 2005. 
MINISTÉRIO DA CIÊNCIA, TECNOLOGIA E INOVAÇÃO- MCTI. Estratégia Nacional de Ciência, Tecnologia e Inovação 2012-2015: Balanço das atividades estruturantes 2011. Brasília: MCTI, 2012. Disponível em: http://www.mct.gov.br/upd_blob/0218/218981.pdf. Acesso em: 20 dez. 2017.

PARRILLI, Mario Davide; HERAS, Henar Alcalde. STI and DUI innovation modes: Scientific-technological and context-specific nuances. Research Policy, Elsevier, n. 45 p.747-756, 2016.

RAMPAZZO, Lino. Metodologia científica: para alunos dos cursos de graduação e pósgraduação. 7. ed. São Paulo: Loyola, 2013, 154p.

SARACEVIC, T. Information science. Journal of American Society for Information Science and Technology, v. 50, n. 12, p. 1051-1063, 1999. Disponível em: http://tefkos.comminfo.rutgers.edu/JASIS1999.pdf. Acesso em 07 jun. 2018.

SOUZA, Janara. As sete teses equivocadas sobre conhecimento científico: reflexões epistemológicas. Ciências \& Cognição: revista interdisciplinar de estudos da cognição, v. 08, p. 143-152, ago. 2006.

SUGAHARA, Cibele Roberta; JANNUZZI, Paulo de Martino. Estudo do uso de fontes de informação para inovação tecnológica na indústria brasileira. Ciência da Informação, Brasília, v. 34, n. 1, p.45-56, jan./abr. 2005.

TIDD, Joe; BESSANT, John; PAVITT, Keith. Gestão para a inovação. 3. ed. São Paulo: Artmed, 2008. 600p.

UNESCO. UNESCO Science Report: towards 2030. França, Paris: UNESCO, 2015. Disponível em: http://unesdoc.unesco.org/images/0023/002354/235406e.pdf. Acesso em: 04 maio 2018.

VEGA-ALMEIDA, Rosa Lidia; FERNÁNDEZ-MOLINA, Juan Carlos; LINARES, Radamés. Coordenadas paradigmáticas, históricas y epistemológicas de la Ciencia de la Información: una sistematización. Information Research, Borâs, Suécia, v.14, n.2, jun. 2009. Disponível em: http://informationr.net/ir/14-2/paper399.html . Acesso em: 28 ago. 2018. 